\title{
Synthesis and Interfacial Characterization of Graft and Random Copolymers of Styrene and 2-Hydroxyethyl Methacrylate
}

\author{
Koichi ITO, Yutaka MASUdA, Takuji SHINTANI, \\ Toshiaki KITANO, and Yuya YAMASHITA* \\ School of Materials Science, Toyohashi University of Technology, \\ Tempaku-cho, Toyohashi 440, Japan \\ *Department of Synthetic Chemistry, Faculty of Engineering, \\ Nagoya University, Furo-cho, Chikusa-ku, Nagoya 464, Japan
}

(Received January 19, 1983)

\begin{abstract}
Polystyrene (PSt) macromonomers with methacrylate end-groups $\left(\mathrm{M}_{1}\right)$ were copolymerized with 2-hydroxyethyl methacrylate (HEMA, $\mathbf{M}_{2}$ ) to give amphiphilic graft copolymers with PSt branches. The monomer reactivity ratio of HEMA was estimated as $r_{2}=1.7 \pm 0.4$. The ${ }^{1} \mathrm{H}$ NMR spectrum of a graft copolymer in methanol revealed a micelle formation with a PSt core, while chloroform caused the formation of a reversed micelle with a PHEMA core. The contact angle of water on polymer films suggested that the PSt segments generally dominate the surface properties of graft copolymers, independent of a composition above $15 \mathrm{wt} \%$ PSt. In contrast, the random copolymers of St and HEMA showed results as expected for a single-phase structure, both by ${ }^{1} \mathrm{H}$ NMR and contact angle.

KEY WORDS Polystyrene Macromonomer / Amphiphilic Graft Copolymer / 2-Hydroxyethyl Methacrylate / Monomer Reactivity Ratio / ${ }^{1}$ H NMR / Selective Micelle Formation / Contact Angle /
\end{abstract}

Recent developments in macromonomer ("macromer") techniques have made possible the preparation of a variety of graft copolymers of well-defined structure and composition, as reviewed by Yamashita. ${ }^{1}$ These tailor-made graft as well as block copolymers have been well characterized as model polymers in order to establish the fundamental structure-property relationship so important to the designing and exploring the unique application of these polymers. For the past several years our attention has been directed to the preparation and characterization of amphiphilic graft copolymers. ${ }^{2-4}$ The present paper describes the preparation of the graft copolymers of styrene (St) and 2hydroxyethyl methacrylate (HEMA) for the purpose of demonstrating their unique properties. The multi-phase structure of these polymers both in solution and solids as revealed by ${ }^{1} \mathrm{H}$ NMR and contact-angle measurements is discussed.

\section{EXPERIMENTAL}

\section{Materials}

All reagents and solvents used for anionic polymerization including end-capping and deactivation were purified by conventional procedures, and finally distilled and sealed under a vacuum line $\left(10^{-5} \mathrm{mmHg}\right)$ into ampoules fitted with breakable seals. Styrene was redistilled over benzophenone sodium just before use for the polymerization. Ethylene oxide (EO) and methacryloyl chloride (MAC) were distilled over calcium hydride and stocked as solutions in benzene. $s$-Butyllithium $(s \mathrm{BuLi})$ was prepared under vacuum from $s$-butyl chloride and lithium in hexane. Unreacted $s$-butyl chloride and excess lithium were removed by evacuation and filtration, respectively, and $s \mathrm{BuLi}$ was sealed as a hexane solution into calibrated breakable ampoules. Benzene was redistilled over $n$-butyllithium.

HEMA (Kishida Chemical Co., Ltd.) and di- 
methylformamide (DMF) were distilled on a $30 \mathrm{~cm}$ Widmer column over calcium hydride under a reduced pressure of argon. Silica-gel plates (Merck, 60F254) for thin layer chromatography (TLC), deuterated solvents $\mathrm{CDCl}_{3}(99.7 \%$, Merck) and $\mathrm{CD}_{3} \mathrm{OD}\left(99 \%\right.$, Merck) for ${ }^{1} \mathrm{H}$ NMR were used as supplied.

\section{Preparation of Polymers}

Graft copolymers were prepared according to Scheme 1. PSt macromonomer $\left(\mathrm{M}_{1}\right)$ was obtained

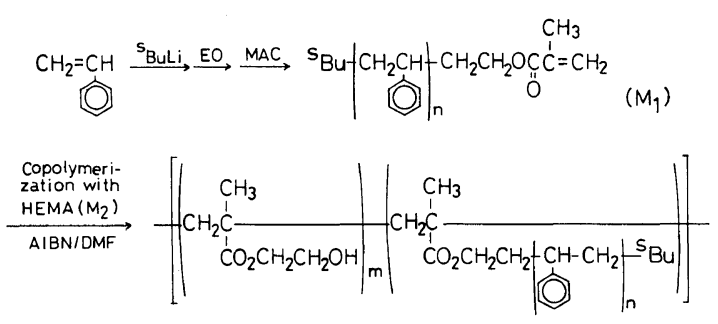

Scheme 1. Preparation of graft copolymers.

by the method of Milkovich, ${ }^{5}$ using a conventional high-vacuum line $\left(10^{-5} \mathrm{mmHg}\right)$ technique. Styrene was polymerized in benzene at room temperature for $1 \mathrm{~h}$ by $s \mathrm{BuLi}$. End-capping by EO and deactivation by MAC were conducted for $0.5 \mathrm{~h}$ each using three- to four-fold excess reagents over $s \mathrm{BuLi}$. The polymers were precipitated out of methanol, reprecipitated from benzene into methanol, and freeze-dried from benzene. Yields were quantitative and molecular weight was close to that expected from the mole ratio in the feed of the monomer to the initiator. The molecular weight distribution was very sharp with $M_{w} / M_{n}$ around 1.1 , judging by the gel permeation chromatography (GPC) given in Table I. The terminal methacrylate double bond was confirmed by ${ }^{1} \mathrm{H}$ NMR peaks at $\delta 5.4$ and 5.9 $\left(=\mathrm{CH}_{2}\right)$ and $\delta 1.8\left(=\mathrm{C}-\mathrm{CH}_{3}\right)$ but their quantitative analysis was difficult because of the very low concentrations. Bromine titration was applied to the macromonomer to assay the double-bond purity above $90 \%$ based on the $M_{n}$ by GPC.

Radical copolymerization of the PSt macromonomers with HEMA was conducted at $60^{\circ} \mathrm{C}$ in an evacuated tube into which the monomers, DMF as a solvent, and $\alpha, \alpha^{\prime}$-azobisisobutyronitrile (AIBN) as an initiator had been weighed. The polymers were precipitated out of water, reprecipitated from tetrahydrofuran into methanol or a mixture with
Table I. Characterization of PSt macromonomers

\begin{tabular}{ccccc}
\hline \multirow{3}{*}{ Run } & \multicolumn{3}{c}{$M_{n}$} & \multirow{2}{*}{$\begin{array}{c}M_{w} / M_{n} \\
\text { GPC }\end{array}$} \\
\cline { 2 - 4 } & Kinetic $^{\mathrm{a}}$ & VPO $^{\mathrm{b}}$ & GPC & \\
\hline PS-5 & - & 3740 & 3180 & 1.09 \\
PS-6 & - & 8050 & 6930 & 1.01 \\
PS-7 & 4400 & 4270 & 4020 & 1.03 \\
PS-8 & 1300 & 1920 & 1790 & 1.12 \\
\hline
\end{tabular}

a $M_{n}$ (kinetic) $=104[\mathrm{M}]_{0} /[\mathrm{I}]_{0}$, where $[\mathrm{M}]_{0}$ and $[\mathrm{I}]_{0}$ are molar concentrations of monomer and $s \mathrm{BuLi}$ in feed, respectively

b Vapor pressure osmometry measured in benzene.

petroleum ether. Unreacted macromonomers were removed by extraction with diethyl ether or hot cyclohexane. The graft copolymers thus obtained were confirmed to have been satisfactorily purified by the fact that GPC showed no peak due to macromonomers and that TLC on silica-gel plates gave no indication of PSt and PHEMA homopolymers developed by ethyl acetate and methanol, respectively. Copolymer compositions were calculated from ${ }^{1} \mathrm{H}$ NMR spectra in $\mathrm{CD}_{3} \mathrm{OD}-\mathrm{CDCl}_{3}$ mixed solvents using the relative intensities of the peaks due to phenyl and ester methylene protons observed at $\delta 6.5-7.0$ and $3.7-4.1$, respectively (see Figure 2), and checked satisfactorily for some samples by the elemental analyses for carbon. The results are summarized in Table II. Runs G-6 to 12 were carried out to relatively low conversions in order to evaluate the monomer reactivity ratio, as will be discussed later.

Random copolymers of St and HEMA, and the homopolymers (PHEMA and PSt) were those prepared by conventional radical polymerization, as characterized in Table III.

\section{Methods}

${ }^{1} \mathrm{H}$ NMR spectra were recorded on JEOL JNM PMX-60 spectrometer operating at $60 \mathrm{MHz}$ and the probe temperature $35^{\circ} \mathrm{C}$. GPC was taken at $40^{\circ} \mathrm{C}$ on JASCO HPLC TRIROTAR-III equipped with a SHODEX column A-802 or A-803 and calibrated with standard polystyrene samples. Tetrahydrofuran was used as the eluent at a flow rate of 1 $\mathrm{ml} \mathrm{min}^{-1}$. Contact angle of water on the air side of polymer film was measured at $20^{\circ} \mathrm{C}$ by a CA-A type apparatus of Kyowakagaku Co., Ltd. Poly- 
Table II. Copolymerization of PSt macromonomer $\left(\mathrm{M}_{1}\right)$ and $\operatorname{HEMA}\left(\mathrm{M}_{2}\right)^{\mathrm{a}}$

\begin{tabular}{|c|c|c|c|c|c|c|c|c|c|c|}
\hline \multirow{2}{*}{ Run } & \multicolumn{3}{|c|}{$\mathbf{M}_{1}$ in feed } & \multirow{2}{*}{$\frac{\text { Time }}{\mathrm{h}}$} & \multirow{2}{*}{$\frac{\text { Conversion }}{w t \%}$} & \multicolumn{2}{|c|}{$\mathbf{M}_{1}$ in copolymer } & \multirow{2}{*}{$\begin{array}{c}M_{n} \times 10^{4} \\
\text { GPC }\end{array}$} & \multirow{2}{*}{$\begin{array}{c}M_{w} / M_{n} \\
\mathrm{GPC}\end{array}$} & \multirow{2}{*}{$\begin{array}{l}\text { Number of } \\
\text { PSt branches }\end{array}$} \\
\hline & $M_{n} / \mathrm{GPC}$ & $w t \%$ & $\mathrm{~mol}^{\circ} \%$ & & & $w t \%$ & $\mathrm{~mol} \%$ & & & \\
\hline G-1 & 4020 & 75 & 8.9 & 137 & - & 72 & 7.7 & 2.88 & 2.33 & 5.5 \\
\hline G-2 & 4020 & 50 & 3.1 & 137 & 89 & 44 & 2.5 & 2.49 & 2.77 & 3.1 \\
\hline G-3 & 4020 & 34 & 1.6 & 137 & 97 & 30 & 1.4 & 2.67 & 1.74 & 2.3 \\
\hline G-4 & 4020 & 25 & 1.1 & 137 & 97 & 20 & 0.8 & 2.41 & 2.07 & 1.4 \\
\hline G-5 & 4020 & 15 & 0.6 & 137 & 100 & 15 & 0.6 & 2.70 & 2.74 & 1.2 \\
\hline G-6 & 3180 & 70 & 8.5 & 2 & 32 & 59 & 5.6 & - & - & - \\
\hline G-7 & 3180 & 57 & 4.5 & 2 & 37 & 43 & 3.0 & - & - & - \\
\hline G-8 & 3180 & 50 & 3.8 & 2 & 33 & 45 & 3.2 & - & - & - \\
\hline G-9 & 3180 & 40 & 3.0 & 1.5 & 28 & 33 & 2.0 & - & - & - \\
\hline G-10 & 3180 & 29 & 1.6 & 1.3 & 25 & 17 & 0.83 & - & - & - \\
\hline G-11 & 3180 & 20 & 1.0 & 1.8 & 38 & 16 & 0.77 & - & - & - \\
\hline G-12 & 3180 & 11 & 0.5 & 1 & 23 & 6 & 0.26 & - & - & - \\
\hline
\end{tabular}

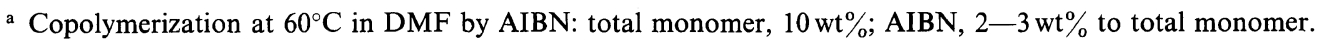

Table III. Preparation and characterization of St $\left(\mathrm{M}_{1}\right)$-HEMA $\left(\mathrm{M}_{2}\right)$ random copolymers and homopolymers

\begin{tabular}{|c|c|c|c|c|c|c|c|c|}
\hline \multirow{2}{*}{ Run } & \multicolumn{2}{|c|}{$M_{1}$ in feed } & \multirow{2}{*}{$\frac{\text { Time }}{\mathrm{h}}$} & \multirow{2}{*}{$\frac{\text { Conversion }}{w t \%}$} & \multicolumn{2}{|c|}{$\mathbf{M}_{1}$ in copolymer } & \multirow{2}{*}{$\begin{array}{c}M_{n} \times 10^{4} \\
\text { GPC }\end{array}$} & \multirow{2}{*}{$\begin{array}{c}M_{w} / M_{1} \\
\text { GPC }\end{array}$} \\
\hline & $w t \%$ & $\mathrm{~mol} \%$ & & & $\mathrm{wt} \%$ & $\mathrm{~mol}^{\circ} \%$ & & \\
\hline $\mathrm{R}-1^{\mathrm{a}}$ & 75 & 79 & 24 & 19 & 76 & 80 & 5.15 & 1.36 \\
\hline $\mathrm{R}-2^{\mathrm{a}}$ & 44 & 50 & 5 & 26 & 46 & 52 & 5.04 & 1.46 \\
\hline $\mathrm{R}-3^{\mathrm{a}}$ & 31 & 36 & 24 & 63 & 30 & 35 & - & - \\
\hline $\mathrm{R}-4^{\mathrm{a}}$ & 17 & 18 & 1.5 & 32 & 19 & 23 & 7.57 & 1.28 \\
\hline PHEMA $^{b}$ & 0 & 0 & 6.8 & 86 & 0 & 0 & - & - \\
\hline $\mathrm{PSt}^{\mathrm{c}}$ & 100 & 100 & - & - & 100 & 100 & 6.15 & 1.69 \\
\hline
\end{tabular}

a Copolymerization at $60^{\circ} \mathrm{C}$ in DMF by AIBN: total monomer, $20 \mathrm{wt} \%$; AIBN, $1 \mathrm{wt} \%$ to total monomer.

b Polymerization of HEMA $\left(20 \mathrm{wt} \%\right.$ ) in DMF at $60^{\circ} \mathrm{C}$, AIBN $2 \mathrm{wt} \%$; [ $\eta$ ] of the polymer was 0.43 in methanol at $25^{\circ} \mathrm{C}$.

c Polystyrene fractionated by benzene-methanol from a product of Mitsubishi Monsanto Co., Ltd.

mer films were prepared on clean slides or Teflon plates by casting from $c a .3 \mathrm{wt} \%$ solutions, followed by slow evaporation of the solvents. A water droplet of $c a .2 \mathrm{~mm} \phi$ was placed on the polymer film and the contact angle was measured in less than one minute to avoid evaporation or expansion of the droplet. No difference was observed in the contact angle depending on the supporting plate (glass or Teflon) or the aging time after preparation or heating treatment.

\section{RESULTS AND DISCUSSION}

Graft copolymers were prepared according to
Scheme 1 with the results summarized in Table II. Molecular weights and distributions were estimated by GPC calibrated with polystyrene, which accounts for, even if roughly, from at least one to six PSt branches per molecule. Although some statistical distributions in composition, sequence length, and in molecular weight are inevitable in the nature of radical copolymerization, ${ }^{6}$ the graft copolymers obtained were found by GPC and TLC measurements to be satisfactorily purified, being free of PSt or PHEMA homopolymers. Since the monomer reactivity ratio is very important in determining trunk-branch distribution and discussing the reactivity of macromonomers, we attempted to es- 
timate this quantity, using the data obtained at relatively low conversions (runs G-6 to 12). The conventional Mayo-Lewis equation is reduced to eq 1 when the mole ratio in the feed is very large so that $\left[\mathrm{M}_{2}\right] /\left[\mathrm{M}_{1}\right] \gg 1$ as in the present case. ${ }^{5}$

$$
\frac{-\mathrm{d}\left[\mathrm{M}_{2}\right]}{-\mathrm{d}\left[\mathrm{M}_{1}\right]}=\frac{1+r_{2}\left[\mathrm{M}_{2}\right] /\left[\mathrm{M}_{1}\right]}{1+r_{1}\left[\mathrm{M}_{1}\right] /\left[\mathrm{M}_{2}\right]} \cong r_{2}\left[\mathrm{M}_{2}\right] /\left[\mathrm{M}_{1}\right]
$$

The reactivity ratio $r_{2}$ of HEMA was calculated using the observed mole ratio of HEMA to PSt macromonomer in the graft copolymer and that in feed, based on the $M_{n}=3180$ of the macromonomer as measured by GPC. The ratio in feed was corrected for a drift, though not a very large one, in the relative concentration during conversion by taking the average of the mole fractions in the feed and those after the observed conversion. The $r_{2}$ value thus obtained was $1.7 \pm 0.4$. The copolymer composition curve is given in Figure 1 in terms of the composition by wt $\%$, since the conventional plots in terms of $\mathrm{mol} \%$ lie quite near the side of $0 \% \mathrm{M}_{1}$. The effect of using a different $M_{n}$ for the macromonomer, 3740 by VPO instead of 3180 by GPC (see Table I), was virtually insignificant in estimating $r_{2}$, which was calculated to be $1.9 \pm 0.4$ in this case.

The Fineman-Ross ${ }^{7}$ or Kelen-Tüdös method $^{8}$ was also applied to the present data to obtain both monomer reactivity ratios as: $r_{1}=-0.2 \pm 9.8$ and $r_{2}=1.6 \pm 0.2$, indicating clearly that this $r_{1}$ value is meaningless. The reason for this is that the copolymerization had to be performed at a very high mole ratio of the comonomer $\left(\mathrm{M}_{2}\right)$ to the high molecular

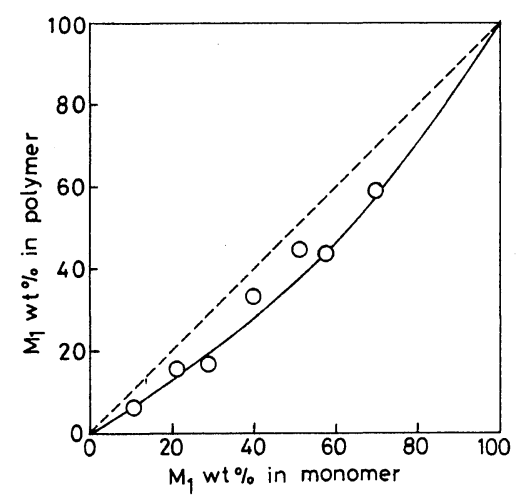

Figure 1. Copolymer composition curve for the copolymerization of the PSt macromonomer $\left(\mathrm{M}_{1}, M_{n}=3180\right)$ and HEMA $\left(\mathrm{M}_{2}\right)$ at $60^{\circ} \mathrm{C}$ in DMF. Solid line is theoretical with $r_{2}=1.7$. weight macromonomer $\left(\mathrm{M}_{1}\right)$ so that the graft copolymers could be satisfactorily analyzed for composition by a conventional method. The $r_{2}$ value, however, is significant enough to assure the approximate estimation of $r_{2}$ according to eq 1 , and $r_{2}$ is reliable for evaluating the reactivity of the macromonomer. The corresponding $r_{1}$ and $r_{2}$ for the copolymerization of methyl methacrylate (MMA) and HEMA ${ }^{9}$ were $r_{1}=0.29$ and $r_{2}=1.05$. Comparison of $1 / r_{2}\left(=k_{21} / k_{22}\right)$ for PSt macromonomer (methacrylate end-group) with that for MMA showed a somewhat lower reactivity $\left(k_{21}\right)$ for the former, suggesting some disturbance toward the reaction of the macromonomer (with a long chain-tail) for the polymer radical. Yamashita et al. ${ }^{10}$ recently reported a similar $r_{2}(2.0$ to 2.3) for the same system with a PSt macromonomer of $M_{n}=14000$ or 23000 . We consider that macromonomer reactivity should be more extensively evaluated before a general discussion is made on the effect of the long chain-tail.

Amphiphilic graft or block copolymers are expected to form micellar aggregates, or even an intramolecular micelle, in a particular solvent, just as they do in solid microphase separation phenomena. This was indeed the case as observed by the ${ }^{1} \mathrm{H}$ NMR spectra of the graft copolymers shown in Figure 2(b) and (c). HEMA-rich copolymer (G-5) was apparently soluble in $\mathrm{CD}_{3} \mathrm{OD}$ to give a clear solution whose spectrum showed only those peaks due to PHEMA segments at $\delta 3.7-4.1$ $\left(\mathrm{OCH}_{2} \mathrm{CH}_{2} \mathrm{O}\right)$ and $\delta 1.0-2.1\left(\mathrm{CH}_{3}, \mathrm{CH}_{2}\right)$. With the addition of $\mathrm{CDCl}_{3}$, the peaks due to the PSt segments also appeared at $\delta 6.5-7.0\left(\mathrm{C}_{6} \mathrm{H}_{5}\right)$. This clearly indicates that the PSt segments insoluble in methanol constitute a micelle core which behaves as a "solid" on the NMR time scale, ${ }^{11}$ consequently their peaks were too broad to be observed. On the other hand, PHEMA segments are too soluble in methanol for a clear solution to be maintained about the PSt core, causing the peaks of only PHEMA segments to appear. Chloroform, a good solvent for PSt segments, destroys the micelle structure in concert with methanol, giving rise to a normal spectrum in the mixed solvent.

Exactly the reverse phenomenon was observed with a PSt-rich graft copolymer (G-1), which showed only those peaks due to PSt segments in $\mathrm{CDCl}_{3}$, indicating the formation of a micelle with a PHEMA core surrounded by PSt segments. This 
(a) $\mathrm{R}-4$
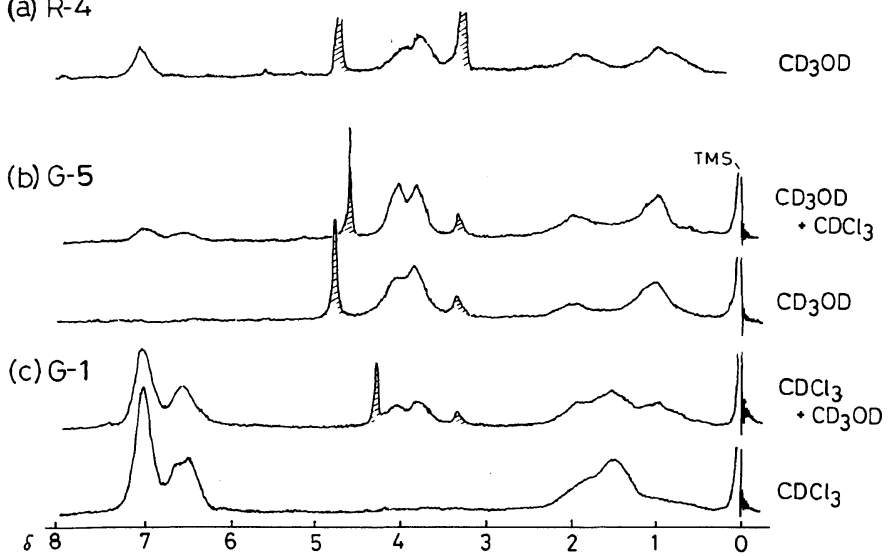

Figure 2. ${ }^{1} \mathrm{H}$ NMR spectra of graft and random copolymers. (a) R-4 in $\mathrm{CD}_{3} \mathrm{OD}$, (b) G-5 in $\mathrm{CD}_{3} \mathrm{OD}$, and in $\mathrm{CD}_{3} \mathrm{OD}-\mathrm{CDCl}_{3}\left(\mathrm{ca} .20 \mathrm{vol} \%\right.$ ), (c) G-1 in $\mathrm{CDCl}_{3}$, and in $\mathrm{CDCl}_{3}-\mathrm{CD}_{3} \mathrm{OD}$ (ca. $20 \mathrm{vol} \%$ ). Hatched peaks are due to $\mathrm{CH}_{3} \mathrm{OH}$.
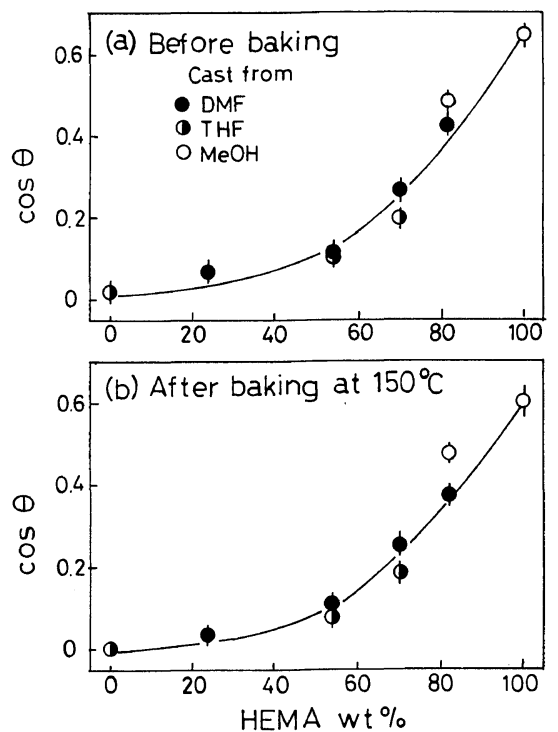

Figure 3. Contact angles of water on random copolymer films.

micelle was destroyed on addition of $\mathrm{CD}_{3} \mathrm{OD}$ to give a normal spectrum. Similar observations have been reported for the block copolymers of poly(St- $b$-ethylene oxide) in water-tetrahydrofuran (THF), ${ }^{12}$ and for those of poly(St- $b$-2-acrylamido2-methylpropanesulfonic acid) in $\mathrm{CCl}_{4}$-water system. ${ }^{13}$ In contrast, the random copolymer showed a normal spectrum even in a single solvent, as shown in Figure 2(a), as evidence for the statistical distribution of St and HEMA units with very short
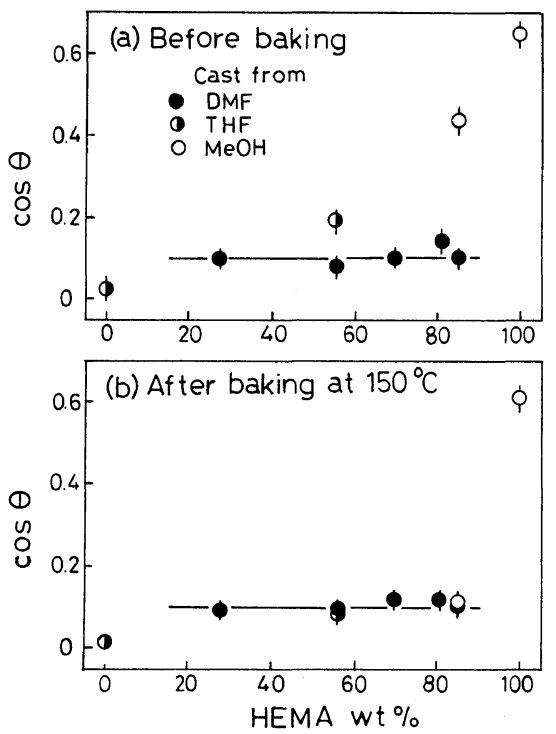

Figure 4. Contact angles of water on graft copolymer films.

sequence lengths which prevent micelle formation.

The surface properties of these polymers were evaluated by the contact angle of water on polymer films cast from appropriate solvents. Measurements were made at $20^{\circ} \mathrm{C}$ before and after the polymer films were heated for $1 \mathrm{~h}$ at $150^{\circ} \mathrm{C}$, a temperature well above the $T_{\mathrm{g}}$ 's of PSt $\left(95^{\circ} \mathrm{C}\right)$ and PHEMA $\left(120^{\circ} \mathrm{C}\right) .{ }^{14}$ The results for random and graft copolymers are given in Figures 3 and 4, respectively. Random copolymers showed, as expected, a 


\section{K. Iто et al.}

smooth change in $\cos \theta$ with composition, becoming more wettable with increasing HEMA (hydrophilic) content, independent of the cast solvent or on thermal history.

The graft copolymers showed very interesting wetting properties. When cast from DMF, a good solvent for both homopolymers, their contactangles were very close to that of PSt and independent of composition, even with a sample $85 \mathrm{wt} \%$ HEMA (G-5). This sample, however, was significantly more wettable when cast from methanol and it became nonwettable after being baked at $150^{\circ} \mathrm{C}$. These results clearly suggest that the surface properties of graft copolymers are also controlled by microphase separation phenomenon. Thus, the polymer cast from methanol, a selective solvent for PHEMA, appears to retain its structure as in solution, i.e., with a PSt core covered with PHEMA. When heated above $T_{\mathrm{g}}$, the structure is rearranged to the most thermodynamically-stable one. It is reasonable to consider that the PSt domains with lower surface energy would generally, or at least eventually, dominate the polymer surface properties, as was actually observed. Electron-microscope observation by Yamashita et al. ${ }^{10}$ showed dominant PSt segments on the surface of the graft copolymer with only $10.9 \mathrm{wt} \%$ PSt, while PHEMA segments constituted a continuous phase in bulk.

In conclusion, simple experiments such as ${ }^{1} \mathrm{H}$ NMR and contact angle measurements showed the multi-phase forming properties of amphiphilic graft copolymers, which are different from the singlephase structure of the random copolymers. Specific interaction of gaseous probes with graft and random copolymers were investigated by inverse gas chromatography, in relation to bulk and surface morphology. The results will be published in a forthcoming paper.
Acknowledgements. This work was supported in part by a Grant-in-Aid for Scientific Research (No. 56550645) from the Ministry of Education. The authors are greatly indebted to Dr. Kazuo Tsutsumi, Toyohashi University of Technology, for the use of the contact angle apparatus, and to $\mathrm{Mr}$. Akihiko Yamanaka for preparation of the randorn copolymers.

\section{REFERENCES}

1. Y. Yamashita, Kobunshi, 31, 988 (1982).

2. K. Ito, N. Usami, and Y. Yamashita, Macromolecules, 13, 216 (1980).

3. Y. Yamashita, K. Ito, H. Mizuno, and K. Okada, Polym. J., 14, 255 (1982).

4. Y. Yamashita, Y. Tsukahara, K. Ito, K. Okada, and T. Tajima, Polym. Bull., 5, 535 (1981).

5. R. Milkovich and M. T. Chiang, US Patent 3,786,916 (1974).

6. Y. Yamashita and $\mathrm{K}$. Ito, in "Kyojugo (Copolymerization)," Kobunshi-Gakkai, Ed., Baifukan, Tokyo, 1975, p 1-58.

7. M. Fineman and S. D. Ross, J. Polym. Sci., 5, 259 (1950).

8. T. Kelen and F. Tüdös, J. Macromol. Sci., Chem., A9, 1 (1975).

9. I. K. Varma and S. Patnaik, Eur. Polym. J., 12, 259 (1976).

10. S. Yamashita, K. Shibatani, K. Takakura, and K. Imai, Kobunshi Ronbunshu, 39, 187 (1982).

11. F. A. Bovey, "High Resolution NMR of Macromolecules," Academic Press, New York, 1972, pp 14, 288.

12. R. Endo, Kobunshi, 24, 612 (1975).

13. H. Konishi, Y. Shinagawa, A. Azuma, T. Okano, and J. Kiji, Preprints, 44th JCS Symposium at Okayama, 1981, p 1542.

14. Y. K. Sung, D. E. Gregonis, G. A. Russel, and J. D. Andrade, Polymer, 9, 1362 (1978). 